\title{
Chronic mastitis is associated with altered ovarian follicle development in dairy cattle
}

\author{
M. M. Rahman, ${ }^{\star}$ M. Mazzilli,† G. Pennarossa, ${ }^{\star}$ T. A. L. Brevini, ${ }^{\star}$ A. Zecconi, $†$ and F. Gandolfi ${ }^{\star 1}$ \\ ${ }^{*}$ Department of Animal Science, and \\ †Department of Animal Pathology, Hygiene and Veterinary Public Health, Università degli Studi di Milano, 20133 Milan, Italy
}

\begin{abstract}
Connection between mastitis and fertility is multifaceted; therefore, several aspects need more elucidation. In particular, the aim was to investigate if naturally occurring chronic mastitis has an effect on ovarian function. At the time of slaughter, a milk sample and both ovaries were collected from 68 cows. The presence and intensity of chronic mastitis was diagnosed by the combined evaluation of bacteriological examination and somatic cell count of the milk of each individual quarter according to the measures of the National Mastitis Council. Animals were divided into 4 groups characterized by a low $(\mathrm{n}=15)$, mild $(\mathrm{n}=14)$, intense $(\mathrm{n}=19)$, or severe $(n=16)$ degree of infection. A count of visible follicles on each ovary was followed by a quantitative analysis of microscopic traits on a selected group of animals $(\mathrm{n}=16)$. The latter included the classification and count of the entire preantral follicle population, and the morphometric analysis of the vascular bed extension and connective stroma in the cortical region. Finally, the expression of growth and differentiation factor-9 (GDF-9) was studied. The number of follicles with diameters ranging from 1 to $3 \mathrm{~mm}$ and 4 to $7 \mathrm{~mm}$ was not affected by the degree of infection. A significant effect of the degree of udder infection was observed on the number of follicles with a diameter larger than $8 \mathrm{~mm}$. Furthermore, the intensity of mastitis had no effect on the number of primordial and primary follicles, but severely affected cows showed a lower number of secondary follicles $(0.5 \pm 0.1$ vs. $0.2 \pm 0.03)$. Quantitative analysis demonstrated a decrease in the density of blood vessels $(6.30 \pm 1.08$ vs. $4.68 \pm 0.28)$ expressed as ratio of vascular bed/total area) and a higher incidence of fibrous stroma (1.60 \pm 0.99 vs. $6.04 \pm 3.08$ expressed as ratio of connective tissue/total area) in the cortical area of the most affected animals. Finally, the level of GDF-9 protein within the oocytes of different follicle size was lower in the animals with the severe form of
\end{abstract}

Received August 9, 2011.

Accepted November 17, 2011.

${ }^{1}$ Corresponding author: fulvio.gandolfi@unimi.it chronic mastitis $(1.34 \pm 0.05$ vs. $0.78 \pm 0.21$ expressed as arbitrary units). In conclusion, decreased fertility of cows with chronic mastitis takes place through an effect on the ovary altering the dynamics of folliculogenesis. Within the ovary, this implies a reduction of the vascular bed and an increase in the fibrotic tissue together with a direct effect on oocyte-specific factors as GDF-9, all of which are essential regulatory elements of folliculogenesis.

Key words: cattle, mastitis, ovary, follicular dynamics

\section{INTRODUCTION}

The constant decrease in fertility in dairy cattle has been a widespread problem for the last few decades (Diskin and Morris, 2008). Pregnancy rates as low as 35 to $45 \%$ are observed in modern high-producing herds (Royal et al., 2000). Such a decrease is largely attributed to the genetic selection that privileged the direct connection between energy intake and milk yield at the expense of other physiological functions, including reproduction (Leroy et al., 2008a).

High milk production is linked to mastitis, the most common disease affecting dairy cows worldwide (Halasa et al., 2007). The first evidence of a relationship between mastitis and decreased fertility was reported 20 yr ago (Moore et al., 1991). Affected cows had long interestrus intervals, even if these first data were contradictory, describing opposite results in the 2 herds under examination. Further studies confirmed that clinical mastitis had a negative effect on fertility when it occurred either before or after the first AI postpartum (Barker et al., 1998; Santos et al., 2004). The negative effect of mastitis on reproductive efficiency is not limited to its clinical form but was observed when the disease remains subclinical (Schrick et al., 2001). Very high milk yield is not an essential prerequisite for mastitis to decrease reproductive performances, as mastitic cows had more days to first service and days to conception than nonmastitic cows in a dual-purpose breed (Nava-Trujillo et al., 2010).

Mastitis can be caused by a variety of pathogenic bacteria both gram-positive and negative, but despite 
some initial observation suggesting that the type of pathogen may have an effect on the incidence of mastitis on fertility (Moore et al., 1991) several studies excluded any influence of the bacteria species (Barker et al., 1998; Schrick et al., 2001; Santos et al., 2004). Recent results indicated that whereas gram-negative experimental acute mastitis has immediate short-term effects on the function of preovulatory follicles, grampositive infection exhibits a long-term effect (Lavon et al., 2011b).

Negative interactions between mastitis and reproductive efficiency can be mediated by several mechanisms. The hypothalamic-pituitary-ovarian axis is a potential target. Experimental intramammary inoculation of pathogens in healthy cows during early lactation indicated that mastitis alters the uterine sensitivity to $\mathrm{PGF}_{2 \alpha}$ and its sensitivity to oxytocin that may decrease embryonic development and quality independently from luteolysis and decrease of progesterone concentrations during pregnancy (Hockett et al., 2000). At the same time, experimental acute udder infection can decrease LH pulsatility with a consequent decrease of estradiol$17 \beta$ production, leading to a lack of estrous expression (Hockett et al., 2005). The effect of an acute administration of Escherichia coli endotoxin (LPS), either i.v. or directly into the mammary gland, during estrus has been studied (Lavon et al., 2008), showing that ovulation is delayed, plasma estradiol concentration is low, and the preovulatory LH surge is low or delayed. Studies on naturally occurring subclinical mastitis confirmed that the same endocrine disruptions were observed in about $30 \%$ of affected animals (Lavon et al., 2010). A more detailed examination of the effects of chronic mastitis on ovarian follicles revealed that an abnormal follicular steroidogenesis was present in the same percentage of infected animals (Lavon et al., 2011a).

The way through which mastitis impairs fertility could be aspecific and common to any inflammatory process. Elevated body temperature, a classical symptom of acute mastitis, is a most likely candidate. It is known that a temperature increase around fertilization and early embryonic development significantly decreases oocyte competence and embryonic survival (Hansen, 2009). Decreased feed intake, another common symptom in animals experiencing clinical infection, may alter energy metabolism and cause further disruption of reproductive function (Hockett et al., 2005; Leroy et al., 2008b).

It is clear that connections between mastitis and fertility are complex and multifaceted. Therefore, several aspects need further elucidation. The aim was to investigate if naturally occurring chronic mastitis has an effect on the ovary.

\section{MATERIALS AND METHODS}

\section{Sample Collection}

Milk samples and both ovaries of each animal were obtained at a local abattoir (Miglio Srl, Pandino, Italy). Milk samples were aseptically collected from each of the 4 quarters shortly before slaughter and immediately stored at $4^{\circ} \mathrm{C}$. Ovaries were kept in sterile saline solution at 32 to $34^{\circ} \mathrm{C}$ and delivered to the laboratory within $2 \mathrm{~h}$ of collection.

\section{Animals and Experimental Groups}

Cows were carefully examined before slaughter and 64 animals were included in the study. Criteria for inclusion were no sign of pathologies other than mastitis, and an age ranging from 27 to $60 \mathrm{mo}$. The presence and the intensity of mastitis was diagnosed by the combined evaluation of bacteriological examination and SCC of the milk of each individual quarter according to the measures of the US National Mastitis Council (NMC, 1999). For each cow, SCC values of the previous 3 mo were retrieved from the regional breeders association database [Associazione Regionale Allevatori della Lombardia (ARAL), Milan, Italy]. Values of bacteriological infection and SCC were divided into 4 classes whose limit values are in Table 1 . The sum of the 2 values gave the total score (TS) for each animal, ranging from 2 to 8 (Table 1 ). Animals were divided into 4 groups characterized by a low (TS 2-4), mild (TS 5), intense (TS 6), or severe (TS 7-8) degree of infection. Animals in the severe group were defined as affected by chronic mastitis having had a SCC $>500,000$ cells $/ \mathrm{mL}$ for at least 3 mo.

\section{Postmortem Macroscopic Examination}

Upon arrival in the laboratory, ovaries were rinsed with sterile saline solution and subjected to morphological evaluation consisting in the measurement of the volume and in the count of all visible follicles. Follicles were grouped in 3 diameter classes: 1 to $3 \mathrm{~mm}, 4$ to 7

Table 1. Reference values used for the classification of the degree of udder infection based on the US National Mastitis Council measures

\begin{tabular}{lccc}
\hline \multicolumn{4}{c}{ Quarter health scoring } \\
\hline $\begin{array}{l}\text { Bacteriological } \\
\text { analysis }\end{array}$ & Score & $\begin{array}{c}\text { SCC } \\
(\times 1,000 \text { cells } / \mathrm{mL})\end{array}$ & Score \\
\hline Negative & 1 & $<200$ & 1 \\
Minor pathogens (CNS) & 2 & $200-500$ & 2 \\
Contaminated & 3 & $501-1,000$ & 3 \\
Major pathogen & 4 & $>1,000$ & 4 \\
\hline
\end{tabular}


$\mathrm{mm}$, and $>8 \mathrm{~mm}$. The number of follicles in each class was counted for each animal and compared among the 4 infection categories.

\section{Quantitative Analysis of Microscopic Measures}

Sample Preparation and Quantification Procedures. Ovaries were sectioned longitudinally and transversally in 4 fragments. Fragments were immersion fixed either in formalin (morphological studies) or in $4 \%$ paraformaldehyde (immunocytochemical analysis) and embedded in paraffin. Sections $(5-\mu \mathrm{m}$ thick) were cut from the cortical region of each ovary, and processed as described below. The surface of each section was measured with the image analyzer software ImageJ (http:// rsb.info.nih.gov/ij; Collins, 2007) so that similar areas were analyzed for each ovary. For each measure taken into consideration, a minimum of 3 sections, $100 \mu \mathrm{m}$ apart, of each ovary of each animal were examined.
Preantral Follicles. The number and type of preantral follicles were recorded for every section considered, counting only follicles with visible oocyte nuclei to avoid duplicate counting in different sections. All follicles in each section were counted and classified. Follicles were classified as primordial (oocyte surrounded by a single layer of flattened granulosa cells), primary (oocyte surrounded by a cuboidal layer of granulosa cells), or secondary (oocyte surrounded by 2 or more layers of cuboidal granulosa cells; Figure 1). The results are expressed as total number of follicles of each type per millimeter squared in each animal.

Extension of the Vascular Bed. To determine the extension of the vascular bed in the cortical region, endothelium was stained with Bandeiraea simplicifolia lectin-I (GSL-I/BSL-I, B-1105; Sigma, Milan, Italy; Alroy et al., 1987). Briefly, deparaffinized sections were rehydrated, washed in PBS, and incubated with $\mathrm{H}_{2} \mathrm{O}_{2}$ $[0.3 \%$ ( vol/vol) in methanol for $30 \mathrm{~min}]$ to suppress

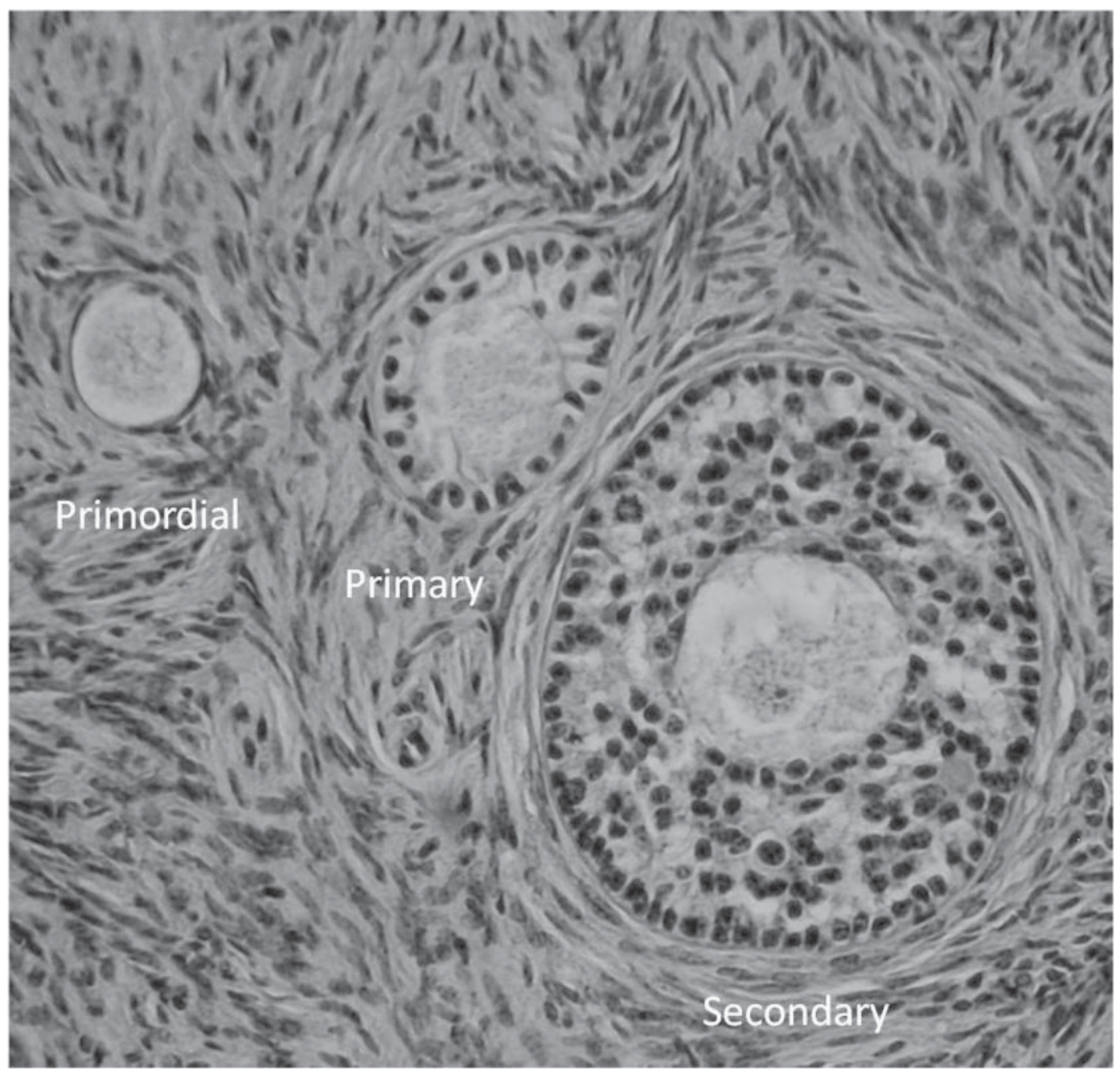

Figure 1. Representative photograph of primordial, primary, and secondary follicles. Section is stained with hematoxylin and eosin. Original magnification $400 \times$ 
Table 2. Effect of the intensity of mammary infection on the distribution of the follicle population (mean \pm $\mathrm{SD})^{1}$

\begin{tabular}{lcccc}
\hline $\begin{array}{l}\text { Degree of } \\
\text { infection (n) }\end{array}$ & $\begin{array}{l}\text { Follicles } \\
1-3 \mathrm{~mm}\end{array}$ & $\begin{array}{c}\text { Follicles } \\
4-7 \mathrm{~mm}\end{array}$ & $\begin{array}{c}\text { Follicles } \\
>8 \mathrm{~mm}\end{array}$ & $\begin{array}{c}\text { Age } \\
\text { mo })\end{array}$ \\
\hline Low (15) & $7.5 \pm 7.0$ & $1.8 \pm 1.8$ & $1.1 \pm 1.1^{\mathrm{a}}$ & $42.7 \pm 11.1$ \\
Mild (14) & $7.6 \pm 4.2$ & $1.3 \pm 2.0$ & $0.3 \pm 0.6^{\mathrm{b}}$ & $41.0 \pm 10.8$ \\
Intense (19) & $7.6 \pm 5.8$ & $1.1 \pm 1.7$ & $0.4 \pm 0.7^{\mathrm{b}}$ & $41.6 \pm 10.5$ \\
Severe (16) & $7.6 \pm 5.1$ & $0.8 \pm 0.9$ & $0.5 \pm 0.6^{\mathrm{ab}}$ & $40.9 \pm 11.6$ \\
$P$-value & 0.87 & 0.22 & 0.004 & 0.69 \\
\hline
\end{tabular}

${ }^{a, b}$ Values within a column with different superscript letters are significantly different.

${ }^{1}$ Data refer to each ovary and were analyzed with Kruskal-Wallis ANOVA on ranks.

the endogenous peroxidase activity. A further rinse in PBS (5 min) was followed by an incubation in $5 \%$ BSA (30 min) to block nonspecific bindings. Sections were incubated with $10 \mu \mathrm{g} / \mathrm{mL}$ of biotinylated lectin at room temperature and specific binding was detected with Vectastain elite ABC kit (peroxidase, Cat. No. PK-6100; Vector Laboratories Inc., Burlingame, CA) according to the manufacturer's protocol. To confirm the specificity of lectin binding, staining of a positive control was carried out by substituting the substrate medium with buffer (PBS) without lectin. Results are expressed as percentage of total area occupied by vascular lumen delimited by lectin-positive endothelium.

The Cortical Stroma. To evaluate the ovarian cortex texture, samples were stained with Masson's trichrome with aniline blue (catalog no. 010802; BioOptica Milano SpA, Milan, Italy), which specifically visualizes connective tissue (Lillie, 1952) and results are expressed as percentage of total area occupied by connective tissue.

Growth and Differentiation Factor-9 Expression. Deparaffinized sections mounted on positively charged slides (SuperFrost Plus, catalog no. 21998; Menzel GmbH \& Co KG, Braunschweig, Germany;) and subjected to antigen retrieval by microwave heating in $1 \mathrm{~m} M$ EDTA solution ( $\mathrm{pH}$ 8.0, Sigma E-9884; Sigma-Aldrich Corp., St. Louis, MO) for $10 \mathrm{~min}$. Sections were immunostained using affinity purified goat polyclonal antibody raised against a peptide mapping near the C-terminus of human growth and differentiation factor-9 (GDF-9; sc-12244; Santa Cruz Biotechnology Inc., Santa Cruz, CA). Primary antibody was used at 1:100 dilution in PBS and incubated overnight at $4^{\circ} \mathrm{C}$ in a humidified chamber. Secondary antibody donkey anti-goat IgG conjugated with Alexa Fluor594 (A-11058, molecular probes; Life Technologies, Monza, Italy) was applied at 1:100 dilution in PBS and incubated for $1 \mathrm{~h}$ at room temperature in a dark room. $\mathrm{Nu}-$ clei were counterstained with DNA-binding fluorescent stain, 4',6-diamidino-2-phenylindole (DAPI, D-8417; Sigma-Aldrich Corp.) for the same period of time. The specificity of primary antibody was verified by incubat- ing the sections with equivalent dilution of blocking peptide (sc-12244; Santa Cruz Biotechnology Inc.) and the primary antibody was omitted in the negative control.

Ovaries from animals with low and severe infection were compared. To minimize technical variability, 1 section from an animal with low infection was placed on the same slide with another from an animal with severe infection so that simultaneous processing in the same conditions was possible. Photographs were taken with the same exposure settings and all of the oocytes present in the section of each animal were examined with a minimum of 10 for each animal. The specific labeling intensity was quantified using an arbitrary intensity scale: 0,1 , and 2 for no, weak, and strong signal, respectively. Specimens were examined in a blinded fashion by 2 independent operators. Results are expressed as mean intensity value \pm standard deviation for each animal.

\section{Statistical Analysis}

Statistical analysis was performed with Sigma Stat 3.1 (Systat Software Inc., Chicago, IL). Statistical significance was assessed using the nonparametric Kruskal-Wallis ANOVA on ranks or the Mann-Whitney rank sum test, as appropriate. Differences were considered significant at $P \leq 0.05$.

\section{RESULTS}

\section{Effect of the Degree of Udder Infection on Ovaries Postmortem Examination}

Sixty-four animals were examined. Based on the National Mastitis Council measures for milk analysis and SCC, the degree of infection of 15 animals was classified as low, of 14 animals as moderate, of 19 as intense, and of 16 as severe. No effect of the degree of infection on the ovarian volume $\left(8.0 \pm 4.2 \mathrm{~mm}^{3}\right)$ was recorded.

The number of follicles in the 3 diameter classes for each ovary of each group is given in Table 2. The 
Table 3. Comparison of the distribution of preantral follicles between the ovaries of animals with low and severe mastitis ${ }^{1}$

\begin{tabular}{lccccc}
\hline $\begin{array}{l}\text { Degree of } \\
\text { infection }\end{array}$ & $\begin{array}{c}\text { Primordial } \\
\text { (follicles } / \mathrm{mm}^{2} ; \\
\mathrm{n} \text { in parentheses) }\end{array}$ & $\begin{array}{c}\text { Primary } \\
\text { (follicles } / \mathrm{mm}^{2} ; \\
\mathrm{n} \text { in parentheses) }\end{array}$ & $\begin{array}{c}\text { Secondary } \\
\left(\text { follicles } / \mathrm{mm}^{2} ;\right. \\
\mathrm{n} \text { in parenthes })\end{array}$ & $\begin{array}{c}\text { Age } \\
(\mathrm{mo})\end{array}$ & $\begin{array}{c}\text { Examined } \\
\text { area }\left(\mathrm{mm}^{2}\right)\end{array}$ \\
\hline Low & $22.4 \pm 6.2$ & $2.2 \pm 1.0$ & $0.5 \pm 0.1$ & $41.1 \pm 10.1$ & $57.3 \pm 2.6$ \\
Severe & $(982)$ & $(101)$ & $(22)$ & & \\
& $20.3 \pm 2.6$ & $2.2 \pm 1.5$ & $0.2 \pm 0.03$ & $42.9 \pm 10.9$ & $56.0 \pm 2.5$ \\
$P$-value & $(1,076)$ & $(100)$ & $(12)$ & 0.74 & 0.31 \\
\hline
\end{tabular}

${ }^{1}$ Data are expressed as mean $\pm \mathrm{SD}$ and were analyzed with the Mann-Whitney rank sum test.

number of follicles with a diameter ranging from 1 to 3 $\mathrm{mm}$ and 4 to $7 \mathrm{~mm}$ was not affected by the degree of infection, but a significant effect was observed on the number of follicles with a diameter $>8 \mathrm{~mm}$.

\section{Quantitative Microscopic Analysis}

The detailed quantitative microscopic analysis was performed on 16 animals, 8 with low $(\mathbf{L})$ and 8 with severe (S) udder infection, chosen at random.

Effect of Mastitis on Preantral Follicle Development. A total area of $906.4 \mathrm{~mm}^{2}$ was examined and a total of 2,494 follicles were classified. Table 3 summarizes the number of each follicle category in the 2 experimental groups. Whereas the intensity of mastitis had no effect on the number of primordial and primary follicles, severely affected cows had a significantly lower number of secondary follicles.

Effect of Mastitis on Ovarian Cortex Vascular Bed. Cortex vascularization was assessed by determining the area occupied by blood vessels, identified by endothelial cell-specific lectin immunostaining, in the cortical sections of both $\mathrm{L}$ and $\mathrm{S}$ groups. In ovaries from L animals, a well-developed capillary network was observed in the cortical stroma where preantral follicles were located. Quantitative analysis showed a significant decrease $(P=0.01)$ in the density of blood vessels in the cortical area of S animals (Table 4 and Figure 2) with respect to $\mathrm{L}$ animals.

Effect of Mastitis on the Extension of Connective Tissue in the Ovarian Cortex. The texture of the ovarian cortex was analyzed with the specific Masson's trichrome stain. The quantitative assessment of connective tissue extension indicated that L ovaries had a significant lower incidence of fibrous stroma than did S ovaries (Table 4 and Figure 3)

Effect of Mastitis on GDF-9 Expression. The level of GDF-9 protein within the oocytes of preantral follicles of different sizes was analyzed by immunohistochemistry. The antibody bound specifically to bovine GDF-9 with a good signal-to-noise ratio that enabled an accurate quantification between $\mathrm{L}$ and $\mathrm{S}$ ovaries. Oocytes within the ovaries of $\mathrm{S}$ animals showed a significantly lower level of this protein than what was found in L animals (Table 5 and Figure 4).

\section{DISCUSSION}

Data indicate an association between chronic mastitis and altered ovarian function. These data support previous findings, indicating that both clinical and subclinical IMI have a negative effect on fertility (Barker et al., 1998; Schrick et al., 2001; Santos et al., 2004) and extend current information suggesting that such a decrease in fertility involves alterations of the ovary and its follicle. It was suggested that chronic IMI could damage the process of folliculogenesis at various time points (Lavon et al., 2011b). Our data support this hypothesis because we observed that both the transition from primary to secondary follicles and the development of the largest follicles were significantly less effective in $\mathrm{S}$ animals. Interestingly, the intermediate stages

Table 4. Comparison of the extension of the vascular bed and of the connective tissue between the ovaries of animals with low and severe mastitis $(\text { mean } \pm \mathrm{SD})^{1}$

\begin{tabular}{lcccc}
\hline $\begin{array}{l}\text { Degree of } \\
\text { infection }\end{array}$ & $\begin{array}{c}\text { Total area } \\
\text { examined for } \\
\text { vascular bed }\left(\mathrm{mm}^{2}\right)\end{array}$ & $\begin{array}{c}\text { Ratio of } \\
\text { vascular bed } \\
\text { total area }\end{array}$ & $\begin{array}{c}\text { Total area } \\
\text { examined for } \\
\text { connective tissue } \\
\text { (fibrous stroma; } \mathrm{mm}^{2} \text { ) }\end{array}$ & $\begin{array}{c}\text { Ratio of } \\
\text { connective } \\
\text { tissue/total area }\end{array}$ \\
\hline Low & $7.16 \pm 2.56$ & $6.30 \pm 1.08$ & $16.77 \pm 7.97$ & $1.60 \pm 0.99$ \\
Severe & $6.03 \pm 2.80$ & $4.68 \pm 0.28$ & $19.67 \pm 8.33$ & $6.04 \pm 3.08$ \\
$P$-value & 0.41 & 0.01 & 0.22 & $<0.001$ \\
\hline
\end{tabular}

${ }^{1}$ Data were analyzed with the Mann-Whitney rank sum test. 

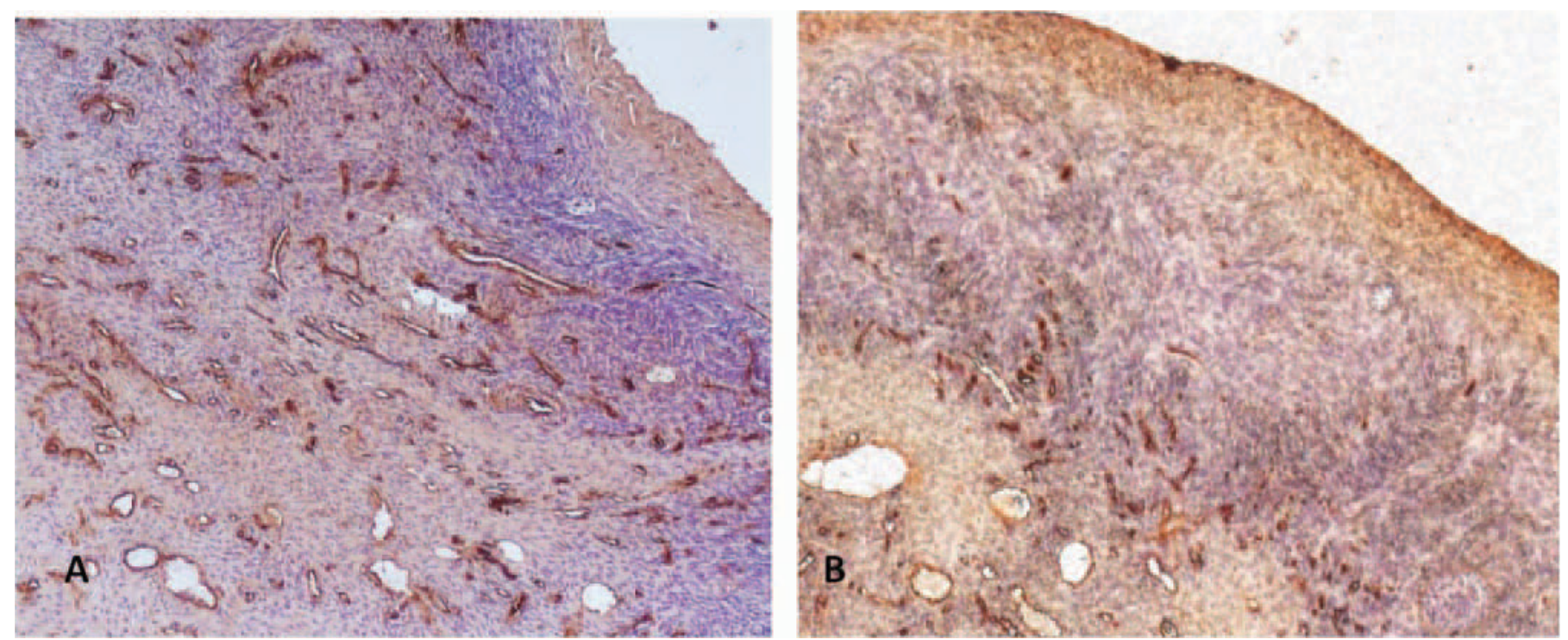

Figure 2. Representative image of blood vessels in the cortical sections of animal with low (A) and severe (B) chronic mastitis, identified by endothelial cell-specific lectin immunostaining. Original magnification $40 \times$. Color version available in the online PDF.

(i.e., follicles with a diameter from 1 to $7 \mathrm{~mm}$ ) were not affected, suggesting that 2 independent mechanisms act simultaneously on the ends of folliculogenesis.

Our data represent the first microscopic description of mastitis-associated alterations of the ovarian cortex with an evident decrease of the vascular bed accompanied by a fibrotic transformation of the stroma. Follicles are individually surrounded by a vascular supply only after antrum formation and the differentiation of both the theca interna and externa takes place, whereas
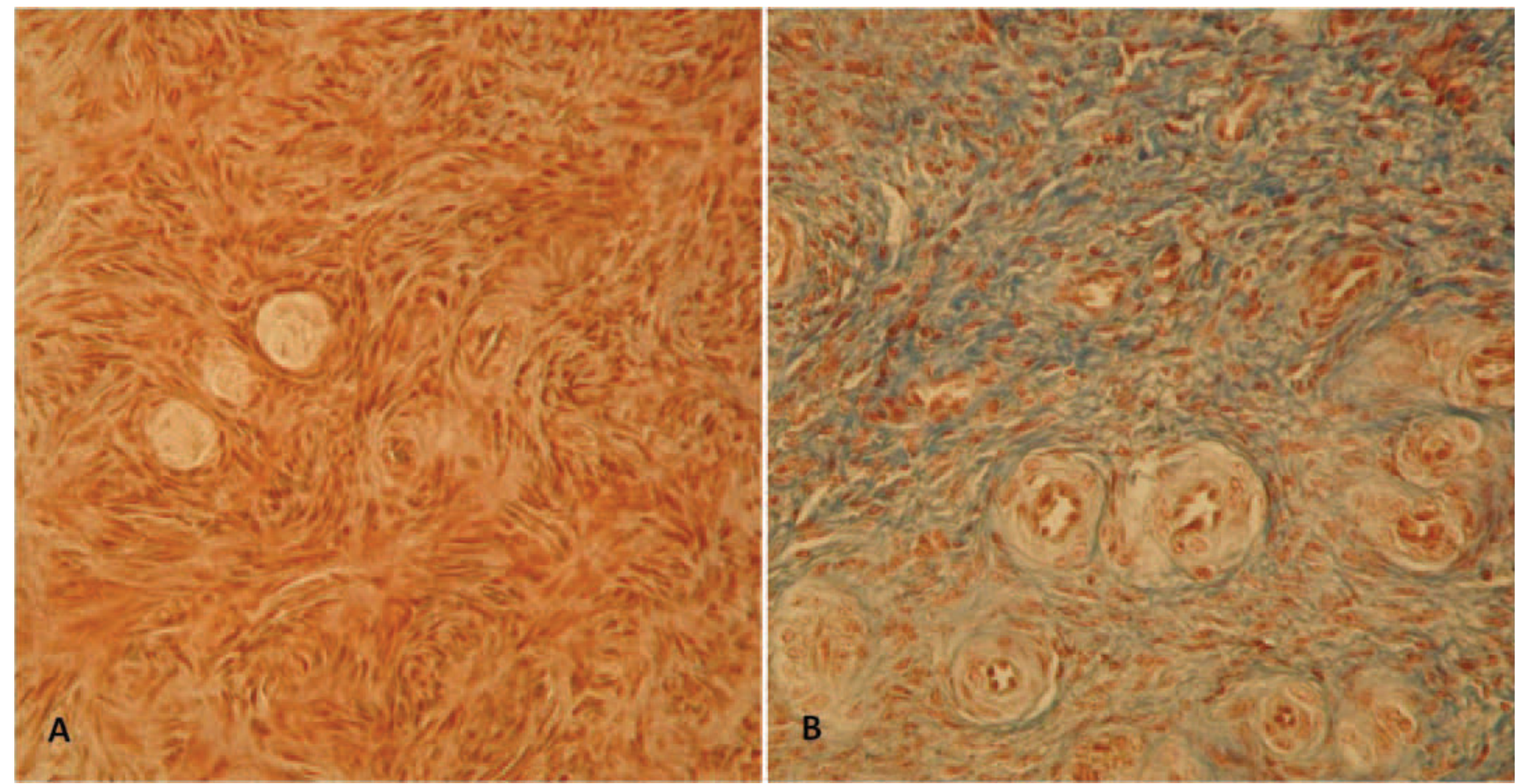

Figure 3. Representative photograph of the quantitative assessment of connective tissue with the specific histochemical Masson's trichrome stain. Panel A: animal with low udder infection; panel B: animal with severe infection. Original magnification $200 \times$. Color version available in the online PDF. 
Table 5. Comparison of growth and differentiation factor-9 (GDF9) expression measured as labeling intensity in all visible oocytes

\begin{tabular}{lcc}
\hline $\begin{array}{l}\text { Degree of } \\
\text { infection }\end{array}$ & $\begin{array}{c}\text { Arbitrary intensity } \\
\text { units (mean } \pm \mathrm{SD})\end{array}$ & $\begin{array}{c}\text { Classified } \\
\text { oocytes }(\mathrm{n})\end{array}$ \\
\hline Low & $1.34 \pm 0.05$ & 88 \\
Severe & $0.78 \pm 0.21$ & 92 \\
$P$-value & $<0.001$ & \\
\hline
\end{tabular}

${ }^{1}$ Data were analyzed with the Mann-Whitney rank sum test.

primordial and primary follicles are irrorated by vessels present in the cortical stroma (Shimizu et al., 2003). A close proximity to a vascular supply is thought to be involved in primordial follicle activation and primary follicle transition to the early preantral stage. The proximity with a capillary loop is thought to be one of the possible mechanisms of early follicular growth, as this process is mainly under the control of intraovarian factors such as growth factors and cytokines (Fortune, 2003), some of which, like the vascular endothelial growth factor, are produced directly by the endothelial cells (Herrmann and Spanel-Borowski, 1998). Therefore, the decreased extension of the vascular bed observed in the ovaries of $\mathrm{S}$ animals would be consistent with the decreased capacity of the primary follicles to proceed through the secondary stage. It would confirm recent in vitro studies showing that the addition of vascular endothelial growth factor into the culture medium allows for a 7 -fold increase in the number of primary follicles that evolve into secondary stage (Yang and Fortune, 2007).

A reduced vascular bed was accompanied by an extension of the area occupied by connective tissue, supporting reports for human ovaries of patients exposed to chemotherapy that often targets vascular development (Meirow et al., 2007) and induced endovascular damage, which triggers vascular complications (Meirow and Nugent, 2001). But, a decrease in the number of primordial and primary follicles was not observed, consistent with the notion that both in cattle (Herrmann and Spanel-Borowski, 1998) and in human (Motta et al., 2002) ovaries, these follicle classes are more abundant in vessel-poor zones. Therefore, they would be more tolerant to a reduction of the vascular bed than the secondary follicles that rely on blood-borne factors for their development.

The expression of GDF-9 in the early stages of folliculogenesis was tested to verify the hypothesis that mastitis has a direct effect on the oocyte. Current data on GDF-9 protein localization in the bovine ovary are mostly limited to the late antral stages where it is present both in the oocyte and in cumulus cells (Hosoe et al., 2011). An oocyte-specific localization of GDF-9 was found from the primordial to the early secondary stage development. This contrasts with the GDF-9 localization in mice, rats, and humans, where it became visible only from the primary stage onward, but is consistent with previous observation in cattle where GDF-9 messenger RNA was found in primordial follicles (Mazerbourg and Hsueh, 2003). Whereas GDF-9 was detectable in both $\mathrm{L}$ and $\mathrm{S}$ animals, the signal was less in the latter. This implies a lower expression of this molecule in $\mathrm{S}$ animals that showed an impaired transition from the primary to the secondary stage of development. A contrasting finding was described in rats supplemented with exogenous GDF-9 whose ovaries showed a significant increase of secondary follicles (Vitt et al., 2000),
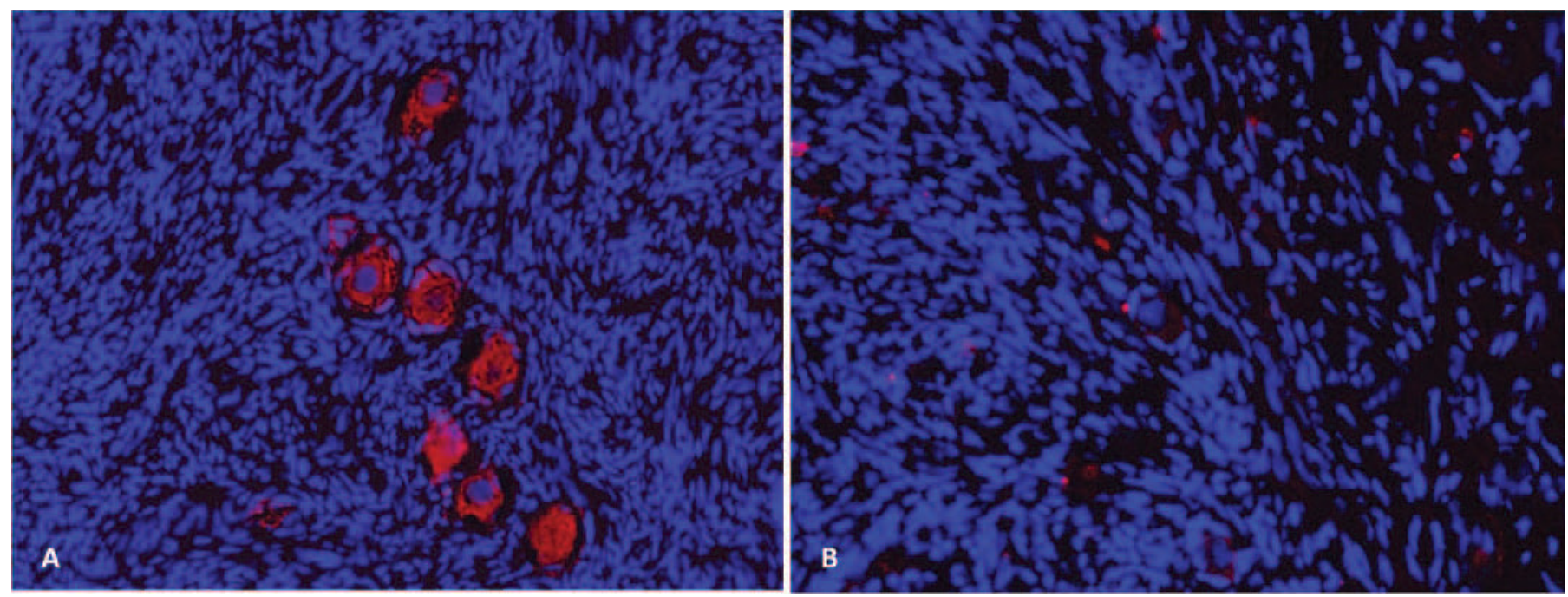

Figure 4. Representative picture of the level of GDF-9 protein within the oocytes analyzed by immunohistochemistry. Panel A: animal with low udder infection; panel B: animal with severe infection. Original magnification $200 \times$. Color version available in the online PDF. 
supporting the hypothesis that in cattle a lack of GDF9 inhibits the primary to secondary follicle transition.

\section{CONCLUSIONS}

An alteration of the ovarian structure takes place in cows affected by chronic mastitis, which involves a reduction of the vascular bed and an increase of the fibrotic tissue, together with a direct effect on oocytespecific factors like GDF-9. All of these are essential regulatory elements of folliculogenesis and could explain, at least in part, how chronic mastitis depresses fertility.

\section{ACKNOWLEDGMENTS}

This work was supported by PRIN 2008-2008X5NWN7 and PUR 2009-ATE-0354 (Italian Ministry of University and Scientific research, Italy). G. Pennarossa is supported by Istituto Nazionale di Genetica Molecolare (INGM, Milan, Italy). The authors are grateful to Roberto Gorrini, Luca Pessina, Alberto Poli, Ariana Vanelli (Department of Animal Sciences, Università degli Studi di Milano, Milan, Italy), and the staff of the local abattoir (Miglio Srl, Pandino, Italy) for their help during the collection and processing of experimental material. We acknowledge the support of COST Action FA0702 (European Union, Brussels, Belgium).

\section{REFERENCES}

Alroy, J., V. Goyal, and E. Skutelsky. 1987. Lectin histochemistry of mammalian endothelium. Histochemistry 86:603-607.

Barker, A. R., F. N. Schrick, M. J. Lewis, H. H. Dowlen, and S. P. Oliver. 1998. Influence of clinical mastitis during early lactation on reproductive performance of Jersey cows. J. Dairy Sci. $81: 1285-1290$.

Collins, T. J. 2007. ImageJ for microscopy. Biotechniques 43:25-30.

Diskin, M. G., and D. G. Morris. 2008. Embryonic and early foetal losses in cattle and other ruminants. Reprod. Domest. Anim. 43(Suppl. 2):260-267.

Fortune, J. E. 2003. The early stages of follicular development: Activation of primordial follicles and growth of preantral follicles. Anim. Reprod. Sci. 78:135-163.

Halasa, T., K. Huijps, O. Østerås, and H. Hogeveen. 2007. Economic effects of bovine mastitis and mastitis management: A review. Vet. Q. 29:18-31.

Hansen, P. J. 2009. Effects of heat stress on mammalian reproduction. Phil. Trans. R. Soc. B 364:3341-3350.

Herrmann, G., and K. Spanel-Borowski. 1998. A sparsely vascularised zone in the cortex of the bovine ovary. Anat. Histol. Embryol. $27: 143-146$.

Hockett, M. E., R. A. Almeida, N. R. Rohrbach, S. P. Oliver, H. H. Dowlen, and F. N. Schrick. 2005. Effects of induced clinical mastitis during preovulation on endocrine and follicular function. J. Dairy Sci. 88:2422-2431.

Hockett, M. E., F. M. Hopkins, M. J. Lewis, A. M. Saxton, H. H. Dowlen, S. P. Oliver, and F. N. Schrick. 2000. Endocrine profiles of dairy cows following experimentally induced clinical mastitis during early lactation. Anim. Reprod. Sci. 58:241-251.

Hosoe, M., K. Kaneyama, K. Ushizawa, K. G. Hayashi, and T. Takahashi. 2011. Quantitative analysis of bone morphogenetic protein 15 (BMP15) and growth differentiation factor 9 (GDF9) gene expression in calf and adult bovine ovaries. Reprod. Biol. Endocrinol. 9:33.

Lavon, Y., G. Leitner, T. Goshen, R. Braw-Tal, S. Jacoby, and D. Wolfenson. 2008. Exposure to endotoxin during estrus alters the timing of ovulation and hormonal concentrations in cows. Theriogenology 70:956-967.

Lavon, Y., G. Leitner, E. Klipper, U. Moallem, R. Meidan, and D. Wolfenson. 2011a. Subclinical, chronic intramammary infection lowers steroid concentrations and gene expression in bovine preovulatory follicles. Domest. Anim. Endocrinol. 40:98-109.

Lavon, Y., G. Leitner, U. Moallem, E. Klipper, H. Voet, S. Jacoby, G. Glick, R. Meidan, and D. Wolfenson. 2011b. Immediate and carryover effects of Gram-negative and Gram-positive toxin-induced mastitis on follicular function in dairy cows. Theriogenology 76:942-953.

Lavon, Y., G. Leitner, H. Voet, and D. Wolfenson. 2010. Naturally occurring mastitis effects on timing of ovulation, steroid and gonadotrophic hormone concentrations, and follicular and luteal growth in cows. J. Dairy Sci. 93:911-921.

Leroy, J. L. M. R., G. Opsomer, A. Van Soom, I. G. F. Goovaerts, and P. E. J. Bols. 2008a. Reduced fertility in high-yielding dairy cows: Are the oocyte and embryo in danger? Part I. The importance of negative energy balance and altered corpus luteum function to the reduction of oocyte and embryo quality in high-yielding dairy cows. Reprod. Domest. Anim. 43:612-622.

Leroy, J. L. M. R., A. Van Soom, G. Opsomer, I. G. F. Goovaerts, and P. E. J. Bols. 2008b. Reduced fertility in high-yielding dairy cows: Are the oocyte and embryo in danger? Part II. Mechanisms linking nutrition and reduced oocyte and embryo quality in high-yielding dairy cows. Reprod. Domest. Anim. 43:623-632.

Lillie, R. D. 1952. Staining of connective tissue. AMA Arch. Pathol $54: 220-233$

Mazerbourg, S., and A. J. W. Hsueh. 2003. Growth differentiation factor-9 signaling in the ovary. Mol. Cell. Endocrinol. 202:31-36.

Meirow, D., J. Dor, B. Kaufman, A. Shrim, J. Rabinovici, E. Schiff H. Raanani, J. Levron, and E. Fridman. 2007. Cortical fibrosis and blood-vessels damage in human ovaries exposed to chemotherapy. Potential mechanisms of ovarian injury. Hum. Reprod. 22:1626-1633

Meirow, D., and D. Nugent. 2001. The effects of radiotherapy and chemotherapy on female reproduction. Hum. Reprod. Update $7: 535-543$

Moore, D. A., J. S. Cullor, R. H. Bondurant, and W. M. Sischo. 1991. Preliminary field evidence for the association of clinical mastitis with altered interestrus intervals in dairy cattle. Theriogenology $36: 257-265$.

Motta, P. M., R. Heyn, and S. Makabe. 2002. Three-dimensional microanatomical dynamics of the ovary in postreproductive aged women. Fertil. Steril. 78:360-370.

Nava-Trujillo, H., E. Soto-Belloso, and A. E. Hoet. 2010. Effects of clinical mastitis from calving to first service on reproductive performance in dual-purpose cows. Anim. Reprod. Sci. 121:12-16.

NMC. 1999. Laboratory Handbook on Bovine Mastitis. National Mastitis Council Inc., Madison, WI.

Royal, M. D., A. O. Darwash, A. P. E. Flint, R. Webb, J. A. Woolliams, and G. E. Lamming. 2000. Declining fertility in dairy cattle: Changes in traditional and endocrine parameters of fertility. Anim. Sci. 70:487-501.

Santos, J. E. P., R. L. A. Cerri, M. A. Ballou, G. E. Higginbotham, and J. H. Kirk. 2004. Effect of timing of first clinical mastitis occurrence on lactational and reproductive performance of Holstein dairy cows. Anim. Reprod. Sci. 80:31-45. 
Schrick, F. N., M. E. Hockett, A. M. Saxton, M. J. Lewis, H. H. Dowlen, and S. P. Oliver. 2001. Influence of subclinical mastitis during early lactation on reproductive parameters. J. Dairy Sci. 84:1407-1412.

Shimizu, T., M. Kawahara, Y. Abe, M. Yokoo, H. Sasada, and E. Sato. 2003. Follicular microvasculature and angiogenic factors in the ovaries of domestic animals. J. Reprod. Dev. 49:181-192.
Vitt, U. A., E. A. McGee, M. Hayashi, and A. J. W. Hsueh. 2000. In vivo treatment with GDF-9 stimulates primordial and primary follicle progression and theca cell marker CYP17 in ovaries of immature rats. Endocrinology 141:3814-3820.

Yang, M. Y., and J. E. Fortune. 2007. Vascular endothelial growth factor stimulates the primary to secondary follicle transition in bovine follicles in vitro. Mol. Reprod. Dev. 74:1095-1104. 